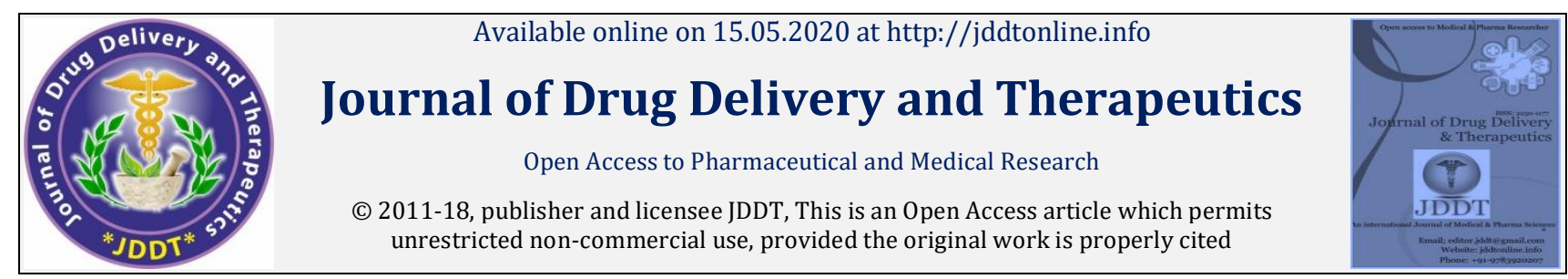

Open Access

Research Article

\title{
Quality of Life Assessment of Hypertensive Patients in a Tertiary Care Teaching Hospital in Jaipur
}

\author{
Sharma Kushagra*, Mishra Nikhil, Kumar Ranjeet \\ Department of Pharmacy Practice, NIMS University Rajasthan, Jaipur, India
}

\begin{abstract}
Background: Hypertension is the well-known risk factor for mortality and morbidity. About 7.1 million population worldwide dies each year due to cause of hypertension. It directly effects persons quality of life. Methods: Total number of 128 Hypertension diagnosed Patient's data were collected under this study who were admitted to the General Medicine wards of tertiary care teaching hospital. WHO BREF questionnaires were given and filled forms by patients were collected. Result: In physical health 42 Patients are with excellent health, 81 Patients are fall under the moderate health and 5 Patients are with poor physical health status. In psychological assessment 36 Patients are with excellent health 83 Patients are fall under the moderate health and 9 Patients are with poor physical health status. In Social relation, 15 Patients are with excellent health, 98 Patients are fall under the moderate health, and 15 Patients are with poor physical health status. In environmental assessment, 57 Patients are with excellent health, 41 Patients are fall under the moderate health and 31 Patients are with poor physical health status. Conclusion: This study has shown overall moderate QOL with mean 3.25 and SD 0.63 among hypertensive patients according all four domains. Physical activities and marital status were important independent factors affecting both domains in QOL. Older age was associated with lower QOL in physical health. Presence of co-morbidity in hypertension patients are an important health issue influencing their satisfaction in physical health. Interventions targeted towards improving QOL of disadvantage patients are ne eded in the setting.
\end{abstract}

Keywords- Mental Health Assessment, WHO BREF, Quality of Life, Hypertension.

Article Info: Received 05 March 2020; Review Completed 18 April 2020; Accepted 22 April 2020; Available online 15 May 2020

Cite this article as:

Sharma K, Mishra N, Kumar R, Quality of Life Assessment of Hypertensive Patients in a Tertiary Care Teaching Hospital in Jaipur, Journal of Drug Delivery and Therapeutics. 2020; 10(3):73-75 http://dx.doi.org/10.22270/jddt.v10i3.4074

*Address for Correspondence: Palakurthi Sushesh Srivatsa, Pinnamraju Durga Nithya

Kushagra Sharma, Department of Pharmacy Practice, NIMS University Rajasthan, Jaipur, India

\section{INTRODUCTION}

Hypertension is the very influential risk factor of renal and cardiovascular diseases; and a well-known risk factor for mortality and morbidity ${ }^{1}$. About 7.1 million populations worldwide die each year due to cause of hypertension ${ }^{2}$. In 2008, about a billion adults aged more than 25 years had hypertension, and one third of the numbers were from developing countries like India ${ }^{3}$. But, despite such high prevalence awareness and blood pressure control are somewhat poor in developing countries, results in lack or incomplete access to information, low healthcare facilities, inappropriate dietary plans, poverty and high cost of treatment or medications 4. Hypertension is a crucial cardiovascular risk factor that may results in serious chronicity to some organs like brain, kidneys, heart and blood vessels; it is considered a genuine public health issue due to its chronicity, high costs of treatment or hospitalization, disability and also the cause of early retirements 5,6. The main risk factors of hypertension include: age, heredity, ethnicity, modern lifestyle, alcohol intake, obesity, stress, gender, excessive use of contraceptives and high sodium intake in diet 6-8. Other factors, both socially and physically, are also indicated not only as cause of hypertension, but because they are often correlated with it (diabetes mellitus, high cholesterol and low educational level) 9 . Thus, since of its close association with lifestyle, Hypertension can be treated or prevented by adopting healthy and good habits.

\section{MATERIAL AND METHODS}

This study was done in the General Medicine wards of tertiary care teaching hospital. The duration of this study is six months. Approval to conduct this study was obtained from Institutional Ethics Committee as well as World Health Organisation, Geneva before starting the study. We also informed patients about the study, as well as their caretakers. Only those who agreed to participate and returned the written consents were included in this study. Total number of 128 Hypertension diagnosed Patient's data were collected under this study who were admitted to the General Medicine wards of tertiary care teaching hospital. W.H.O. BREF questionnaires (English) were given and filled 
forms by patients were collected. Collected data were analysed by using Microsoft Excel 2016.

\section{RESULT}

Four domains of WHO QoL BREF i.e. (Physical Health Assessment, Psychological Assessment, Social Relationship Assessment, Environmental Assessment) were demonstrated adequate reliability in this study. Out of 128 Patients, 84 males and 44 females were participated in Quality of life assessment by WHO QoL BREF questionnaire.

\section{Domain 1 - Physical Health Assessment}

Out of 128 Patients, 42 (33\%) Patients are with excellent health in which Males are 3 and Females are 39, 81 (63\%) Patients are fall under the moderate health in which Males are 79 and Females are 2, and $5(4 \%)$ Patients are with poor physical health status in which Males are 2 and Females are 3.

Table 1: Physical health assessment

\begin{tabular}{llllll}
\hline Serial No. & Status & No. of Males & No. of Females & Total & Total \% \\
\hline $\mathbf{1 .}$ & Excellent & 3 & 39 & 42 & $33 \%$ \\
\hline $\mathbf{2 .}$ & Moderate & 79 & 2 & 81 & $63 \%$ \\
\hline $\mathbf{3 .}$ & Poor & 2 & 3 & 5 & $4 \%$ \\
\hline
\end{tabular}

\section{Domain 2 - Psychological Assessment}

Out of 128 Patients, 36 (28\%) Patients are with excellent health in which Males are 34 and Females are 2, 83 (64\%)
Patients are fall under the moderate health in which Males are 43 and Females are 42 , and $9(8 \%)$ Patients are with poor physical health status in which Males are 7 and Females are 2 .

Table 2: Psychological assessment

\begin{tabular}{llllll}
\hline Serial No. & Status & No. of Males & No. of Females & Total & Total \% \\
\hline $\mathbf{1 .}$ & Excellent & 34 & 2 & 36 & $28 \%$ \\
\hline $\mathbf{2 .}$ & Moderate & 43 & 42 & 83 & $64 \%$ \\
\hline 3. & Poor & 7 & 2 & 9 & $8 \%$ \\
\hline
\end{tabular}

\section{Domain 3 - Social Relationship Assessment}

Out of 128 Patients, 15 (12\%) Patients are with excellent health in which Males are 14 and Female is 1, 98 (64\%)
Patients are fall under the moderate health in which Males are 58 and Females are 40, and $15(12 \%)$ Patients are with poor physical health status in which Males are 12 and Females are 3.

Table 3: Social relationship assessment

\begin{tabular}{llllll}
\hline Serial No. & Status & No. of Males & No. of Females & Total & Total \% \\
\hline 1. & Excellent & 14 & 1 & 15 & $12 \%$ \\
\hline 2. & Moderate & 58 & 40 & 98 & $64 \%$ \\
\hline $\mathbf{3 .}$ & Poor & 12 & 3 & 15 & $12 \%$ \\
\hline
\end{tabular}

\section{Domain 4 - Environmental Assessment}

Out of 128 Patients, 57 (44\%) Patients are with excellent health in which Males are 57 and Female is 0, 41 (32\%)
Patients are fall under the moderate health in which Male is 0 and Females are 41, and 31 (24\%) Patients are with poor physical health status in which Males are 27 and Females are 3.

Table 4: Environmental assessment

\begin{tabular}{|c|c|c|c|c|c|}
\hline Serial No. & Status & No. of Males & No. of Females & Total & Total \% \\
\hline 1. & Excellent & 57 & 0 & 57 & $44 \%$ \\
\hline 2. & Moderate & 0 & 41 & 40 & $32 \%$ \\
\hline 3. & Poor & 27 & 3 & 31 & $24 \%$ \\
\hline
\end{tabular}

Table 5: Mean and SD of domains

\begin{tabular}{lllll}
\hline Serial No. & Domains & Total Population & Mean & SD \\
\hline 1. & Physical Health Assessment & 128 & 3.2 & 0.75 \\
\hline $\mathbf{2 .}$ & Psychological Assessment & 128 & 3.4 & 0.65 \\
\hline $\mathbf{3 .}$ & Social-Relationship Assessment & 128 & 3.1 & 0.47 \\
\hline $\mathbf{4 .}$ & Environmental Assessment & 128 & 3.3 & 0.65 \\
\hline Total & & & $\mathbf{3 . 2 5}$ & $\mathbf{0 . 6 3}$ \\
\hline
\end{tabular}




\section{DISCUSSION}

Among 128 patients, Quality of life of hypertensive patients is moderate in respect of Physical assessment, Psychological assessment, Social Relationship assessment is $63 \%, 64 \%$ and $63 \%$ respectively and Environmental assessment is excellent i.e. 44\%. Our study shows that majority of patients fall under a moderate category in psychological assessment and in respect of Environmental assessment majority of patients falls under excellent category. In our study analysis of how the domain scores varies according to many factors like demographic status, economic status, physical and environmental status. A decrease in QOL was observed with age in physical assessment. Our result is somewhat similar to result of other studies in Vietnam ${ }^{10,11 .}$

\section{CONCLUSION}

This study has shown overall moderate QOL with mean 3.25 and SD 0.63 among hypertensive patients according to all four domains. Physical activities and marital status were important independent factors affecting both domains in QOL. Older age was associated with lower QOL in physical health. Presence of co-morbidity in hypertension patients are an important health issue influencing their satisfaction in physical health. Interventions targeted towards improving QOL of disadvantage patients are needed in the setting.

\section{ACKNOWLEDGMENT}

We express our sincere gratitude to Prof. (Dr.) Balvir S. Tomar (Chancellor \& Chairman, NIMS University Rajasthan, Jaipur), Dr. Ashish Kumar Sharma (Principal, NIMS Institute of Pharmacy) for giving us a chance to explore the world of pharmacy practice and to do research work in this esteemed university. Dr. Ravindra Pal Singh (Dean, NIMS Institute of Pharmacy) for his support and advice. Last but not the least we would like to express our sincere gratitude to our family members who ingrained us with all the necessary values and ambition to successfully complete this study. Above all are eternally thankful to GOD almighty for his blessings on us as well as those around us throughout the study.

\section{Conflict of Interest- Nil}

\section{REFERENCES}

1. Kearney PM, Whelton M, Reynolds K, Muntner P, Whelton PK He J: Global burden of hypertension: analysis of worldwide data. Lancet 2005, 365(9455):217-223.

2. Son PT, Quang NN, Viet NL, Khai PG, Wall S, Weinehall L, Bonita R, Byass P: Prevalence, awareness, treatment and control of hypertension in Vietnam-results from a national survey. J Hum Hypertens 2012, 26(4):268-280.

3. World Health Organization: Global Status Report on Noncommunicable Diseases 2010. Geneva: World Health Organization; 2011:22.

4. Ibrahim MM, Damasceno A: Hypertension in developing countries. Lancet 2012, 380(9841):611-619.

5. Péres DS, Magna JM, Viana LA. Portador de hipertensão arterial: atitudes, crenças, percepções, pensamentos e práticas. Rev Saúde Pública. 2003;37(5):635-42.

6. Reis MG, Glashan RQ. Adultos hipertensos hospitalizados: percepção de gravidade da doença e de qualidade de vida. Rev Latino-am Enfermagem. 2000;9(3):51-7.

7. Feijão AM, Gadelha FV, Bezerra AA, Oliveira AM, Silva MS, Lima JW. Prevalência de excesso de peso e hipertensão arterial, em população urbana de baixa renda. Arq Bras Cardiol. 2005;84(1):29-33.

8. Simonetti JP, Batista L, Carvalho LR. Habitos de salud y factores de riesgo en pacientes con hipertensión arterial. Rev Latino-am Enfermagem. 2002;10(3):415-22.

9. Arslantas D, Ayranci U, Unsal A, Tozun M. Prevalence of hypertension among individuals aged 50 years and over and its impact on health related quality of life in a semi-rural area of western Turkey. Chin Med J (Engl). 2008;121(16):1524-31.

10. Van Minh H, Byass P, Chuc NT, Wall S: Patterns of health status and quality of life among older people in rural Viet Nam. Global Health Action 2010, 3: doi: 10.3402/gha.v3i0.2124.

11. Ha et al.: Quality of life among people living with hypertension in a rural Vietnam community. BMC Public Health 2014 14:833. 